\title{
FACE MASK FOR COVID-19: A SOCIAL RESPONSIBILITY
}

\section{SIRISHA DEEPTHI SORNAPUDI ${ }^{1} \&$ MEENU SRIVASTAVA ${ }^{2}$}

${ }^{l}$ Research Scholar, Department of Textiles \& Apparel Designing, College of Community and Applied Sciences, MPUAT, Udaipur, Rajasthan, India

${ }^{2}$ Professor and Head, Department of Textiles \& Apparel Designing, College of Community and Applied Sciences, MPUAT, Udaipur, Rajasthan, India

\begin{abstract}
The world is currently facing a pandemic in the form of Covid-19 for which a cure is yet to be found. This pandemic has no geographical barrier and every human being is susceptible to it. The preventive prophylaxis advised from time to time by WHO and CDC includes proper coughing etiquette, hand wash, stay at home, social distancing and lastly use cloth masks in the event of limited access to high level respiratory protection worn by health care workers, such as N95 respirators and surgical masks. Covering the face with a fabric mask made at home using breathable fabrics is the new norm for all the denizens of earth. This review article attempts to throw light on various aspects related to facemask and their role in containing the spread of droplet infection.
\end{abstract}

KEYWORDS: Covid-19, Face Mask, Pandemic, Social Distance, Social Responsibility, Stay Home \& Stay Safe

Received: Mar 25, 2020; Accepted: Apr 15, 2020; Published: May 02, 2020; Paper Id.: IJASRJUN20201

\section{INTRODUCTION}

Covid-19 spreads through respiratory droplets released when an infected person coughs, sneezes or speaks. Healthy individuals may also be infected by touching a contaminated surface and then subsequently their eyes, mouth or nose. Infectious aerosols remain in the air for almost 9 hours after release. Adoption of adequate preventive measures like frequent washing of hands, using face masks that cover nose and mouth properly can help protect healthy individuals from contracting the virus. Both World Health Organization and Centre for Disease Control recommend that various face masks viz. N95, surgical and homemade are effective in prevention of $\mathrm{nCoV}$ infection. Homemade cloth masks made with any textile material do have the power to block aerosols, although the particle filtration efficiency of those are yet to be tested, researched and reported by the scientific community.

\section{REVIEW OF LITERATURE}

MacIntyre et al. (2015) compared the efficacy of cloth masks to medical masks in hospital healthcare workers $(\mathrm{HCW})$. A first ever randomised clinical trial of cloth masks and medical masks involving 1607 $\mathrm{HCW}$ was taken up by the researchers. It was concluded that caution needs to be exercised against the use of cloth masks as there is an increased risk of infection among the HCW due to moisture retention, reuse and poor filtration. For cloth masks to be used in resource-poor settings, more research should be taken up and guidelines have to be updated.

A study by Davies et al.(2013) examined the efficiency of homemade masks as a viable alternative to 
commercial face masks in arresting aerosol transmission. Several materials like $100 \%$ cotton t-shirt, scarf, tea towel, pillowcase, anti-microbial pillowcase, linen, silk, etc. were evaluated for the capacity to block bacterial and viral aerosols. Twenty one healthy volunteers made their own face masks from cotton t-shirts; the masks were then tested for fit. The number of microorganisms isolated from coughs of healthy volunteers wearing their homemade mask, a surgical mask, or no mask was compared using several air-sampling techniques. The results showed that the median-fit factor of the homemade masks was one-half that of the surgical masks. Both masks significantly reduced the number of microorganisms expelled by volunteers, although the surgical mask was 3 times more effective in blocking transmission than the homemade mask. It was concluded that a homemade mask should only be considered as a last resort to prevent droplet transmission from infected individuals.

Rengasamy, Eimer and Shaffer (2010) evaluated some common fabrics and cloth masks which showed a wide variation in penetration values for polydisperse $(40-90 \%)$ as well as monodisperse aerosol particles in the $20-1000 \mathrm{~nm}$ range (40-97\%) at $5.5 \mathrm{~cm} \mathrm{~s}^{-1}$ face velocity. For both polydisperse and monodisperse aerosols, the penetration levels obtained were higher than that of $\mathrm{N} 95$ masks but these levels were very much in the range for surgical masks in earlier studies.

Robert et al. (2009) studied on aerosol penetration through clothing and individual protective equipment. The results indicate that aerosol deposition on the body is low even though they might easily pass through air permeable fabrics. Two factors limit the aerosol deposition rate. First, being the volume of air flow through layers of fabrics is less, thereby having an impact of the amount of the aerosol depositing on the skin. Second, being the aerosol deposition rate is low for particle sizes that can penetrate through fabrics. The physics that allows aerosols to penetrate through fabrics also couples the aerosols to the air flow as it exists. This means that even though the fabrics had a high penetration of aerosols during swatch tests (of up to $95 \%$ of particles), less than a few percent deposited on the skin.

\section{TYPES OF MASKS}

- $\quad$ N95 Respirator masks - are considered to be highly efficient in blocking 95 percent of particles of 0.3 microns or larger. Medical and paramedical staff must use them while treating infected patients. Not suggested for use by common man (7). The features of N95 mask (6) are :

- N: Respirator Rating Letter Class. It stands for "Non-Oil" meaning that if no oil-based particulates are present, then you can use the mask in the work environment.

- 95: Masks ending in a 95 , have a 95 percent efficiency.

- .3 microns: The masks filter out contaminants like dusts, mists and fumes. The minimum size of .3 microns of particulates and large droplets won't pass through the barrier.

- Material: The filtration material on the mask is an electrostatic non-woven polypropylene fiber.

- Valve: Some disposable N95 masks have an optional exhalation valve which reduces exhalation resistance.

- Surgical masks-they are rectangular shaped and pleated having elastic ear loops. It filters about 60 to 80 percent of particles. It offesr only limited protection from inhaling small particles (7). 
- Homemade cloth masks-fabric, style and fit of the sewn mask decides its effectiveness.

\section{CDC DIRECTIONS FOR HOMEMADE CLOTH MASKS}

Centre for Disease Control advices that the general public use cloth masks as a means of protection from COVID-19. The use of these cloth masks can help reduce the spread of virus through aerosols, help asymptomatic patients from spreading the virus through droplets of saliva or discharge from the nose. The home made cloth masks are an additional measure to social distancing and good hygienic practices.

A cloth face covering should

- Fit the face snugly ensuring that there is no leakage of droplets from sides

- Secured to the ears with ear loops or ties

- Made up of multiple layers of fabric

- Allow free breathing without difficulty

- Can be laundered at home without damage and change of shape

CDC recommends that facemasks may be made with

- Double layered cotton cloth

- T-shirt

- Bandana

The detailed instructions are available on their website (2). It may be prudent that the masks can be used only once and washed before using them back again. The used masks may not be mixed with other garments while laundering. Masks may be removed without touching any part of the face except the loops that hold them in place. Washing hands immediately after removing masks is advisable.

\section{SUITABLE MATERIALS AND FABRICS FOR A HOMEMADE CLOTH FACEMASK}

Cotton fabrics are by far the most suitable for making a facemask. A woven material might not be as good as a nonwoven in trapping the smallest aerosols. An outer layer of woven fabric backed by a second layer of non woven interfacing is more likely to trap the lightest of the aerosols travelling through the masks. The non woven layer has the possibility to capture the particulate air and entrap it. In short, the aerosol does not get a straight path to migrate out. Both the layers should have to be made from cotton (3). A HEPA filter vacuum bag free (not made from fibreglass) can be the base material to make the masks as it filters $99.9 \%$ of dust and pollen (4). Although use of HEPA filter bag is not scientifically studied and reported, one can presume that it offers some form of protection from contagious virus. HEPA filter fabric can also be inserted in between two cotton layers to offer additional protection(5). A microfiber fabric for the inner layer may also be a good substitute for HEPA filter

Irrespective of the type of fabric used to make the facemask, the following points should be given due importance:

- Adequate sealing of the mask to the face with a double tape which ensures that no air escapes or leaks out of the side of the mask. In addition, it also gives a good fit to the wearer. 
- A metal/ plastic strip that rests on the top of the nose bridge gives a personalised fit and is more comfortable.

\section{COMMON HOUSEHOLD MATERIALS WITH WHICH MASKS CAN BE MADE ARE}

flannel (2 layers), high count bedsheets/pillow covers (2 layers), t-shirts (2 layers), tightly woven tea towels, polyester outer layer, a paper towel between two fabric layers.

\section{Advantages of the Fabric Masks}

- Washable

- Reusable

- Sterilizable

- Good alternative in case of non availability of N95/Surgical masks

\section{CONCLUSIONS}

Desperate times call for desperate measures. Masks are a social responsibility on part of a common man to contain the spread of coronavirus. It helps in trapping the contagious droplets from coughs and sneezes. It will also prevent the aerosol leaks into the surrounding air, thus minimising the spread of the contagion. Coupled with social distancing and hand washing, homemade face masks with cloth have the capacity to reduce the risk of contracting the deadly viruses. Wearing the mask at all times without lowering to uncover the nostrils, flip one ear off to talk or rest on the neck also become a social responsibility on part of the wearer.

There is an urgent need for scientific research to be taken up to study the capability of the cloth face masks to block the microbial/ viral aerosol and be as competent as the N95 or surgical masks. Simple measures like a fit test at the hospitals may be taken up to ascertain the efficacy of the face masks. 'A one size fits all' fabric face mask solution would be ideal to come up with. This requires an in depth research of suitable fabrics, a design that gives an ideal fit to all face types and special fabric finishes which minimise the aerosol transmission. A universal cloth mask adoption by the general public in the ensuing months is the best way to fight against Coronavirus at an individual level.

\section{REFERENCES}

1. Davies, A., Thompson, K.-A., Giri, K., Kafatos, G., Walker, J., \& Bennett, A. (2013). Testing the Efficacy of Homemade Masks: Would They Protect in an Influenza Pandemic? Disaster Medicine and Public Health Preparedness, 7(04), 413-418. doi:10.1017/dmp.2013.43

https://www.cdc.gov/coronavirus/2019-ncov/prevent-getting-sick/diy-cloth-face-coverings.html

2. Adil Ghalib Fadil, "Knowledge and Practice Regarding Infection Control among Dental Students at Basra University College of Dentistry, Iraq", International Journal of General Medicine and Pharmacy (IJGMP), Vol. 5, Issue 6, pp. 35-46

https://www.youtube.com/watch? $v=C p b J F k 311$ Lw\&feature $=$ youtu.be

https://www.youtube.com/watch? $v=$ W6d3twpHwis

3. Ava Rani Phukan, Swapna Choudhury \& Minti Gogoi, "Designing \& Construction of Protective Clothing for Tea Garden Worker of Assam", International Journal of Humanities and Social Sciences (IJHSS), Vol. 5, Issue 6, pp. 1-8

https://www.youtube.com/watch?v=ZnVk12sFRkY 
https://www.honeywell.com/en-us/newsroom/news/2020/03/n95-masks-explained

https://www.nytimes.com/2020/04/10/well/live/coronavirus-face-masks-guides-protection-personal-protective-equipment.html

4. Anwar Kadhim Al-Saffar, "The Effect of Mixture (Sidr Extract with Hydrogen Peroxide) in the Disinfection of Hospital Instrument", International Journal of Botany and Research (IJBR), Vol. 4, Issue 3, pp. 7-10

5. SamyRengasamy, Benjamin Eimer, Ronald E. Shaffer, Simple Respiratory Protection-Evaluation of the Filtration Performance of Cloth Masks and Common Fabric Materials Against 20-1000 nm Size Particles, The Annals of Occupational Hygiene, Volume 54, Issue 7, October 2010, Pages 789-798, https://doi.org/10.1093/annhyg/meq044

6. Pasupuleti LP Bharati\& Kezia Rani Badithi, "Pupil Dilations Detect Iris Liveness Detection”, International Journal of Computer Science Engineering and Information Technology Research (IJCSEITR), Vol. 6, Issue 2, pp. 41-50 https://bmjopen.bmj.com/content/5/4/e006577.responses\#covid-19-shortages-of-masks-and-the-use-of-cloth-masks-as-a-lastresort https://papers.ssrn.com/sol3/papers.cfm?abstract_id=3567438 
